\title{
ANÁLISE DE CUSTOS E DESPESAS EM UMA PREFEITURA DA REGIÃO NOROESTE DO RS, COM ENFOQUE NO COMPARATIVO DE GASTOS COM TRANSPORTE ESCOLAR PRÓPRIO E TERCEIRIZADO
}

\author{
ANALYSIS OF COSTS AND EXPENSESI IN A TOWN HALL OF THE NORTHWEST \\ REGION OF RS, WITH A COMPARATIVE APPROACH TO SPENDS WITH OWN AND \\ OUTSOURCED SCHOOL TRANSPORT
}

\author{
Niriane Machado de Moura \\ Instituto Cenecista de Ensino Superior \\ de Santo Ângelo - CNEC/IESA, Santo Ângelo, RS, Brasil. \\ E-mail: nirianemachado@gmail.com \\ Daiane Ribas Moraes \\ Instituto Cenecista de Ensino Superior \\ de Santo Ângelo - CNEC/IESA, Santo Ângelo, RS, Brasil. \\ E-mail:daiaribas@yahoo.com.br \\ Rosemary Gelatti \\ Instituto Cenecista de Ensino Superior \\ de Santo Ângelo - CNECIIESA, Santo Ângelo, RS, Brasil. \\ E-mail: merygelatti@hotmail.com \\ Zélia Maria Mirek \\ E-mail: zeliamirek@via-rs.net
}

Recebido em: 19.04.2017 - Aceito em: 14.09.2017

\section{RESUMO}

O presente trabalho pretende demonstrar a importância da contabilidade nas organizações, enfatizando que a contabilidade pública está cada vez mais presente no cenário organizacional. Tal afirmativa se justifica, pois procura evidenciar normas e legislações que regem organizações públicas, especificamente no âmbito municipal. $O$ estudo é realizado em um ente público municipal da região, analisando-se a melhor forma de oferecer o serviço de transporte escolar aos alunos do município, procurando simultaneamente diminuir o valor despendido em função dessa necessidade. Por questão a ser resolvida, tem-se o comparativo do custo por quilômetro rodado de veículos próprios em relação a terceirizados, procurando evitar gastos extra orçamentários. A pesquisa se classifica como exploratória com abordagem quantitativa, elaborada por meio de análise documental e também estudo de caso da Prefeitura de São Miguel das Missões/RS. Concluiu-se que o transporte próprio é economicamente mais viável que o terceirizado.

PALAVRAS-CHAVE: Contabilidade; Orçamento; Despesa; Transporte Escolar. 


\section{ABSTRACT}

This paper intends to demonstrate the importance of accounting in organizations, emphasizing that public accounting is increasingly present in the organizational scenario. Such an affirmation is justified because it seeks to evidence norms and laws governing public organizations, specifically at the municipal level. The study is carried out in a municipal public entity in the Northwest region of RS, analyzing the best way to offer school transport service to the city students, while seeking to reduce the amount spent in function of this necessity. As a matter to be solved, there is the comparison of the cost per kilometer of own vehicles compared to outsourced. The research is classified as exploratory with a quantitative approach, elaborated through documentary analysis and also a case study of the analyzed Town Hall. It was concluded that the own transport is economically more viable than the outsourced.

KEYWORDS: Accounting; Budget; Expense; School Transport.

\section{INTRODUÇÃO}

A Contabilidade Pública como instrumento de apoio e controle nas organizações é atualmente matéria de constante e proveitosa utilidade a seus usuários, bem como se aprimora e atualiza a cada dia em todas as suas faces. As demonstrações contábeis devem ser elaboradas de forma ética e coerente na contabilidade, seja na área municipal, estadual ou federal. Em se tratando da área municipal, no âmbito educacional, questiona-se: qual o melhor método de transporte a ser utilizado pelo ente público na busca de economia, levando em consideração as condições oferecidas pelos serviços, tanto municipais próprios quanto terceirizados?

Para responder à questão, definiu-se o objetivo geral: comparar o custo por quilômetro rodado dos veículos próprios em relação ao custo do quilômetro rodado dos veículos terceirizados. Os objetivos específicos são: calcular os custos com todos os tipos de gastos relacionados aos veículos da frota municipal, em específico de três modelos de conduções do transporte próprio, e compará-los aos valores gastos com empresas prestadoras de serviço de transporte terceirizado. $\mathrm{O}$ estudo será realizado por meio da análise de dados, informações fornecidas pelo ente público, relatórios de despesas gerais da frota e com pessoal da Secretaria de Educação do município. Busca-se pesquisar todos os tipos de gastos com transporte escolar no período de um ano, analisando-se, assim, a melhor forma de oferecer o serviço aos alunos do município, procurando simultaneamente diminuir o valor despendido com essa necessidade. 
O interesse pela temática deu-se por ser um tema que gera muitas dúvidas no setor público. O comparativo entre transporte terceirizado e próprio é um estudo abrangente, que pode, ao final, propiciar uma decisão econômica para o ente público e auxiliar o gestor na tomada de decisão futura.

O presente trabalho está estruturado da seguinte forma: nesta introdução, é feito um breve relato sobre o que será abordado e são apresentados a justificativa e o objetivo do estudo. Após, trata-se da revisão da literatura que embasou a fundamentação do trabalho. No seguimento, apresentam-se a metodologia utilizada, os resultados e as possíveis soluções; e, por último, as considerações finais da pesquisa e as referências consultadas.

\section{REFERENCIAL TEÓRICO}

Esta seção aborda aspectos dos serviços de transporte escolar na organização pública, a legislação relacionada, bem como a concessão de benefícios por outros entes públicos ao município estudado, em virtude de essa prestação de serviço ocorrer de forma direta ou, em alguns casos, terceirizada. Entre os autores utilizados nesta pesquisa, estão Kohama (2013), Piscitelli e Timbó (2012), Andrade (2013) e Silva (2014), os quais apontam seu entendimento sobre a contabilidade pública e a legislação aplicada.

\subsection{Contabilidade pública}

A contabilidade é a ciência que estuda e controla as variações do patrimônio no decorrer de um período de tempo. Nessa linha de pensamento, a contabilidade pública constitui uma das subdivisões da Contabilidade Aplicada a diferentes tipos de atividades em entidades. Seu campo de atuação é, assim, o das pessoas jurídicas de Direito Público Interno, tais como a União, Estados, Distrito Federal, Municípios e suas autarquias, e o seu objetivo é estudar, controlar e organizar o patrimônio público e suas mutações.

Entende-se, nos tempos atuais, segundo Kohama (2013, p. 25):

[...] a Contabilidade como uma técnica capaz de produzir, com oportunidade e fidedignidade, relatórios que sirvam à administração no processo de tomada de decisões e de controle de seus atos, demonstrando, por fim, os efeitos produzidos por esses atos de gestão no patrimônio da entidade.

A Contabilidade aplicada à Administração Pública, seja na área federal, estadual, municipal ou distrital, é regulamentada pela Lei nº 4.320 (BRASIL, 1964), de 17 de 
março de 1964, a qual especifica as normas gerais para elaboração e controle dos orçamentos e balanços, de acordo com o art. 163, inciso I, da Constituição Federal.

Conforme Kohama (2013, p. 25):

\begin{abstract}
A Contabilidade Pública é um dos ramos mais complexos da ciência contábil e tem por objetivo captar, registrar, acumular, resumir e interpretar os fenômenos que afetam as situações orçamentárias, financeiras e patrimoniais das entidades de direito público interno, ou seja, a União, Estados, Distrito Federal e Municípios, através de metodologia especialmente concebida para tal, que se utiliza de contas escrituradas segundo normas específicas que constituem o Sistema Contábil Público.
\end{abstract}

O Sistema Contábil é uma estrutura de informações para identificar, mensurar, avaliar, registrar, controlar e evidenciar atos e fatos da gestão do patrimônio público, a fim de orientar decisões, prestação de contas e instrumentalização do controle social (KOHAMA, 2013). Conforme Kohama (2013, p. 54), "a Contabilidade é um instrumento que proporciona à Administração as informações e controles necessários à melhor condução dos negócios públicos”.

Sabe-se que a Contabilidade deve ser bem utilizada; caso contrário, ela não será útil nem eficaz ao trabalho realizado, sendo alvo de auditoria e apontamentos de órgãos fiscalizadores do Estado e da União. As demonstrações contábeis devem ser elaboradas de forma ética e coerente na Contabilidade como um todo, com observância de princípios e regras, seja na área pública, seja privada.

\title{
2.1.1 Orçamento público
}

O orçamento é um instrumento que expressa a alocação dos recursos públicos, sendo operacionalizado por meio de diversos programas, que constituem a integração do Plano Plurianual com o orçamento (Piscitelli \& Timbó, 2012).

Segundo Andrade (2013, p. 43):

Orçamento Público ou orçamento-programa é a materialização do planejamento do Estado, quer na manutenção de sua atividade (ações de rotina), quer na execução de seus projetos (ações com início, meio e fim). Configura o instrumento do Poder Público para expressar seus programas de atuação, discriminando a origem e o montante dos recursos (receitas) a serem obtidos, bem como a natureza e o montante dos dispêndios (despesas) a serem efetuados.

Sabe-se que, para a aprovação do projeto do orçamento pelo legislativo, antes deverá ser feita uma audiência pública para explanação e apreciação do projeto pela população, para que esta esteja ciente do que o Executivo planeja executar durante o período em questão. 
Conforme Piscitelli e Timbó (2012, p. 55):

Em relação aos orçamentos, os resultados fiscais podem ser equilibrados, deficitários ou superavitários. O Governo tem buscado resultados primários positivos (superávits), com o objetivo de, pelo menos, estabilizar a relação dívida pública/Produto Interno Bruto - PIB.

De acordo com o art. $1^{\circ}$ da Lei Complementar $n^{\circ} 101$, de 4 de maio de 2000 (BRASIL, 2000):

$\S 1^{\circ} \mathrm{A}$ responsabilidade na gestão fiscal pressupõe a ação planejada e transparente, em que se previnem riscos e corrigem desvios capazes de afetar o equilíbrio das contas públicas, mediante o cumprimento de metas de resultados entre receitas e despesas e a obediência a limites e condições no que tange à renúncia de receita, geração de despesas com pessoal, da seguridade social e outras, dívidas consolidada e mobiliária, operações de crédito, inclusive por antecipação de receita, concessão de garantia e inscrição em Restos a Pagar.

O orçamento público deve ser elaborado pelos gestores do município, contadores e demais servidores que trabalhem diretamente na administração e alocação de recursos.

\subsubsection{Receita pública}

Parte-se da ideia de que "receita é um termo utilizado mundialmente pela contabilidade para evidenciar uma variação ativa resultante do aumento de ativos e/ou da redução de passivos de uma entidade, aumentando a situação líquida patrimonial qualquer que seja o proprietário". (Silva, 2014, p. 87)

O Manual de contabilidade aplicado ao setor público - MCASP (Ministério da Fazenda, 2014, p. 41) traz a classificação das receitas públicas:

Em sentido amplo, os ingressos de recursos financeiros nos cofres do Estado denominam-se receitas públicas, registradas como receitas orçamentárias, quando representam disponibilidades de recursos financeiros para o erário, ou ingressos extraorçamentários, quando representam apenas entradas compensatórias. Em sentido estrito, chamam-se públicas apenas as receitas orçamentárias.

Conforme Silva (2014), as Receitas Orçamentárias podem ser correntes ou de capital. São exemplos de receitas correntes: Receita Tributária, Receita de Contribuições, Receita Patrimonial, Receita Agropecuária, Receita Industrial, Receita de Serviços, Transferências Correntes e Outras Receitas Correntes. Já as receitas de capital compreendem: Operações de Crédito, Alienação de Bens, Amortização de Empréstimos, Transferências de Capital e Outras Receitas de Capital. 
Conforme Piscitelli e Timbó (2012), a receita pública percorre três estágios: previsão, lançamento, arrecadação e recolhimento. A previsão é o primeiro estágio da receita e corresponde aos valores que a lei do orçamento consignar, pois são estimativas de receitas que se originam de estudos de previsão, antes de compor o projeto de lei orçamentária (Kohama, 2013).

Nota-se que o segundo estágio da receita orçamentária, denominado lançamento, segundo Kohama (2013, p. 85),

[...] é um ato administrativo que visa à identificação e individualização do contribuinte ou devedor, com os respectivos valores, espécies e vencimentos, ou seja, procedimento administrativo que permite verificar a ocorrência do fato gerador da obrigação correspondente, calcular o montante devido, identificar o devedor e, se for o caso, propor a aplicação da penalidade cabível.

Na acepção de Piscitelli e Timbó (2012), há três espécies de lançamento: direto ou de ofício, por declaração e por homologação (autolançamento).

A arrecadação se configura como o terceiro estágio da receita orçamentária na contabilidade pública. Piscitelli e Timbó (2014, p. 144) afirmam que

[...] a arrecadação se caracteriza pela transferência, pelo depósito em favor, em nome do Tesouro, das obrigações dos contribuintes - das pessoas físicas e jurídicas - perante o Poder Público. Muitas vezes tais compromissos são saldados por meio de depositários, quando estes retêm, descontam de outras pessoas tributos e contribuições devidos.

Também o MCASP (2014, p. 56) menciona que, segundo o art. 35 da Lei $n^{\circ} 4.320 / 1964$, pertencem ao exercício financeiro as receitas nele arrecadadas, o que representa a adoção do regime de caixa para o ingresso das receitas públicas.

De acordo com o MCASP (2014, p. 56), há ainda um quarto estágio, que compreende "[...] a transferência dos valores arrecadados à conta específica do Tesouro, responsável pela administração e controle da arrecadação e programação financeira, observando-se o princípio da unidade de tesouraria ou de caixa [...]".

Só através do recolhimento, em conta específica, é que se pode dizer que os recursos estarão efetivamente disponíveis para utilização pelos gestores financeiros, de acordo com a programação que for estabelecida, no entendimento de Piscitelli e Timbó (2014). 


\subsubsection{Despesa pública}

Despesa pública caracteriza um dispêndio de recursos do patrimônio público, representado por uma saída de recursos financeiros, imediata - com redução de disponibilidades - ou mediata - com reconhecimento dessa obrigação (Piscitelli \& Timbó, 2012).

Conforme Kohama (2013, p. 98):

Constituem despesa pública os gastos fixados na lei orçamentária ou em leis especiais e destinados à execução dos serviços públicos e dos aumentos patrimoniais; à satisfação dos compromissos da dívida pública; ou ainda à restituição ou pagamento de importâncias recebidas a título de cauções, depósitos, consignações etc.

Conforme Piscitelli e Timbó (2012, p. 156), "a exemplo da receita, a despesa também apresenta diferentes estágios, que compreendem procedimentos, operações com finalidade específica. [...] tais estágios são o empenho, a liquidação e o pagamento".

Segundo Kohama (2013), a despesa pública classifica-se em dois grandes grupos, a saber: Despesa Orçamentária e Despesa Extraorçamentária. Segundo o mesmo autor, a despesa orçamentária é aquela que depende de autorização legislativa para ser realizada, isto é, precisa de crédito orçamentário correspondente. A despesa extraorçamentária é aquela paga à margem da lei orçamentária e não depende de autorização legislativa (Piscitelli \& Timbó, 2012).

Conforme a legislação vigente no Brasil (Lei n 4.320/1964), a despesa passa pelas seguintes fases: fixação, empenho, liquidação e pagamento.

Considerada o primeiro estágio da despesa, a fixação constitui-se na determinação, por meio de estudos e cálculos fundamentados, do montante total a ser registrado como valor máximo orçamentário a ser consumido pela Administração Pública na execução do orçamento (Andrade, 2013).

Empenho é o ato prévio da autoridade competente reconhecendo e criando, para o Estado, a obrigação de pagamento, pendente ou não, de implemento de condição. Materializa-se por meio de documento chamado "nota de empenho" e oficializa-se com a baixa de despesa na dotação orçamentária. A realização do empenho é a garantia de que existe o crédito necessário para a liquidação de um compromisso assumido, sendo proibida a realização de qualquer despesa sem empenho prévio (Andrade, 2013).

Segundo o MCASP (2014, p. 101):

Quando o valor empenhado for insuficiente para atender à despesa a ser realizada, o empenho poderá ser reforçado. Caso o valor do empenho exceda o montante da despesa realizada, o empenho deverá ser anulado parcialmente. Será anulado totalmente quando o objeto do contrato não tiver sido cumprido, ou ainda, no caso de ter sido emitido incorretamente. 
Conforme Kohama (2013), a dispensa da emissão da nota de empenho, evidentemente, não dispensa o empenho, quer dizer, a dedução da importância para a realização da despesa devidamente autorizada.

A liquidação se apresenta como o terceiro estágio de uma despesa, após o reconhecimento da despesa, por meio da emissão da nota de empenho ao fornecedor.

Por sua vez, o pagamento consiste na entrega de numerário ao credor por meio de cheque nominativo, ordens de pagamentos ou crédito em conta e só pode ser efetuado após a regular liquidação da despesa. A ordem de pagamento só pode ser exarada em documentos processados pelos serviços de contabilidade, no que consta na Secretaria do Tesouro Nacional (STN, 2014).

\subsubsection{Licitação}

A licitação é o processo administrativo regulado pela Lei n 8.666/1993 (Brasil, 1993), pelo qual o ente público faz a aquisição de produtos e serviços por meio de critérios de seleção mais vantajosos para o interesse público.

Conforme Silva (2014, p. 121):

Licitar significa realizar uma competição, um certame, e podemos definir como procedimento administrativo vinculado, pelo qual a Administração Pública seleciona a melhor proposta para celebração de um contrato, buscando adquirir um produto ou a prestação de um serviço.

Pode-se verificar as formas de aquisição de bens ou serviços por meio de licitação no art. 22 da Lei n 8.666/1993 (Brasil, 1993):

Art. 22. São modalidades de licitação:

I - concorrência;

II - tomada de preços;

III - convite;

IV - concurso;

$\mathrm{V}$ - leilão.

$\S 1^{\circ}$ Concorrência é a modalidade de licitação entre quaisquer interessados que, na fase inicial de habilitação preliminar, comprovem possuir os requisitos mínimos de qualificação exigidos no edital para execução de seu objeto.

$\S 2^{\circ}$ Tomada de preços é a modalidade de licitação entre interessados devidamente cadastrados ou que atenderem a todas as condições exigidas para cadastramento até o terceiro dia anterior à data do recebimento das propostas, observada a necessária qualificação. $\S 3^{\circ}$ Convite é a modalidade de licitação entre interessados do ramo pertinente ao seu objeto, cadastrados ou não, escolhidos e convidados em número mínimo de 3 (três) pela unidade administrativa, a qual afixará, em local apropriado, cópia do instrumento convocatório e o estenderá aos demais cadastrados na correspondente especialidade 
que manifestarem seu interesse com antecedência de até 24 (vinte e quatro) horas da apresentação das propostas.

$\S 4^{\circ}$ Concurso é a modalidade de licitação entre quaisquer interessados para escoIha de trabalho técnico, científico ou artístico, mediante a instituição de prêmios ou remuneração aos vencedores, conforme critérios constantes de edital publicado na imprensa oficial com antecedência mínima de 45 (quarenta e cinco) dias.

A modalidade de licitação a ser usada será determinada pelos limites previstos no art. 23 da Lei $n^{\circ} 8.666 / 1993$, analisando-se o valor que será contratado ou adquirido:

I - Para obras e serviços de engenharia:

a) convite - até $R \$ 150.000,00$ (cento e cinquenta mil reais);

b) tomada de preços - até $\mathrm{R} \$ 1.500 .000,00$ (um milhão e quinhentos mil reais);

c) concorrência: acima de $\mathrm{R} \$ 1.500 .000,00$ (um milhão e quinhentos mil reais);

II - para compras e serviços, exceto os de engenharia:

a) convite - até $\mathrm{R} \$ 80.000,00$ (oitenta mil reais);

b) tomada de preços - até $R \$ 650.000,00$ (seiscentos e cinquenta mil reais);

c) concorrência - acima de $\mathrm{R} \$ 650.000,00$ (seiscentos e cinquenta mil reais).(Brasil, 1993).

Seguindo esse pensamento, entende-se que o ente público não pode fazer nada que a lei não autorize, nem adquirir nada sem que antes tenha sido feito todo o processo anteriormente citado, exceto nos casos de compra direta, quando se tratar de pouco valor aquisitivo, e de uma dispensa de licitação autorizada.

\subsubsection{Origem dos recursos para custeio do transporte escolar próprio e terceirizado}

Os recursos que custeiam o transporte escolar são oriundos de arrecadação própria e também do programa Manutenção e Desenvolvimento do Ensino (MDE), do Fundo Nacional de Desenvolvimento da Educação (FNDE), e do Programa Estadual de Apoio ao Transporte Escolar no Rio Grande do Sul (Peate).

$\mathrm{Na}$ Lei de Diretrizes e Bases da Educação Nacional (LDB), Lei n 9.394/1996 (com acréscimo da Lei $n^{\circ} 10.709 / 2003$ ), pode-se verificar, no art. 208, que:

O dever do Estado com a educação será efetivado mediante a garantia de: [...] VII - atendimento ao educando, em todas as etapas da educação básica, por meio de programas suplementares de material didático-escolar, transporte, alimentação e assistência à saúde. (redação dada pela Emenda Constitucional nº59, de 2009).

O estado repassa aos municípios parte de seus recursos, previstos em lei. Em contrapartida, segundo o art. 11, da LDB (Brasil, 1996): 
Os municípios incumbir-se-ão de: [...] VI - assumir o transporte escolar dos alunos da rede municipal (incluído pela Lei $n^{\circ} 10.709$, de 31/7/2003). Parágrafo único. Os Municípios poderão optar, ainda, por se integrar ao sistema estadual de ensino ou compor com ele um sistema único de educação básica.

Ainda conforme $\mathrm{o}$ art. $4^{\circ}$ e $\mathrm{o}$ art. 70 da Lei $\mathrm{n}^{\circ} 9.394$, de 20 de dezembro de 1996 (Brasil, 1996):

Art. $4^{\circ} \mathrm{O}$ dever do estado com educação escolar pública será efetivado mediante a garantia de: [...] VIII - atendimento ao educando, em todas as etapas da educação básica, por meio de programas suplementares;

Art. 70 Considerar-se-ão como de manutenção e desenvolvimento do ensino as despesas realizadas com vistas à consecução dos objetivos básicos das instituições educacionais de todos os níveis, compreendendo as que se destinam à:

[...] VIII - aquisição de material didático-escolar e manutenção de programas de transporte escolar.

Cabe aos estados articular-se com os respectivos municípios, para prover o disposto na Lei $n^{\circ}$ 10.709, de 31 de julho de 2003 (Brasil, 2003), a qual alterou a LDB, de forma a melhor atender aos interesses dos alunos.

O Ministério da Educação, ainda, trabalha com dois programas voltados ao transporte de estudantes: o Caminho da Escola e o Programa Nacional de Apoio ao Transporte do Escolar (Pnate), os quais atendem a alunos moradores da zona rural, segundo o Portal do FNDE (2016).

A Lei $n^{\circ}$ 10.880, de 09 de junho de 2004, que instituiu o Pnate, tem o objetivo de oferecer transporte escolar aos alunos da educação básica pública, residentes em área rural, por meio de assistência financeira, em caráter suplementar, aos estados, ao Distrito Federal e aos municípios (Brasil, 2004).

Nesse sentido, também a Lei n 11.494, de 20 de junho 2007 (Brasil, 2007) dispõe sobre um programa que oferece auxílio aos municípios no transporte escolar, o Manutenção e Desenvolvimento da Educação Básica (MDE). No seu art. 18, a lei dispõe que:

Nos termos do $\S 4^{\circ}$ do art. 211 da Constituição Federal, os Estados e os Municípios poderão celebrar convênios para a transferência de alunos, recursos humanos, materiais e encargos financeiros, assim como de transporte escolar, acompanhados da transferência imediata de recursos financeiros correspondentes ao número de matrículas assumido pelo ente federado.

De acordo com o art. $2^{\circ}$ do Decreto $n^{\circ} 45.465$, de 30 de janeiro de 2008, que regulamenta a Lei $n^{\circ} 12.882$, de 03 de janeiro de 2008, a qual institui o Peate/RS (Rio Grande do Sul, 2008): 
Art. $2^{\circ}$ - Por intermédio do PEATE/RS, o Estado repassará recursos financeiros para financiamento do transporte escolar aos Municípios que realizarem o transporte dos alunos da educação básica, da rede pública estadual, residentes no meio rural de seu território, distantes dois quilômetros da escola pública mais próxima, ou para escola da rede pública estadual localizada em outro Município, desde que constatada a real necessidade.

Segundo o art. $4^{\circ}$ da Lei $n^{\circ} 12.882$, de 03 de janeiro de 2008 (Rio Grande do Sul, 2008), o repasse dos recursos do Peate/RS destina-se ao pagamento de despesas de manutenção de transporte escolar, executado de forma direta ou terceirizada, direta quando os veículos são do patrimônio público ou terceirizada quando o serviço não é executado pelo ente público, e sim por empresas que prestam serviço de transporte.

\section{MÉTODOS DE PESQUISA}

De acordo com Gil (2010), pode-se definir pesquisa como o procedimento racional e sistemático que tem como objetivo proporcionar respostas aos problemas que são propostos.

O objetivo da pesquisa aplicada está na procura de solução de problemas, qual seja, redução de dispêndios orçamentários. Também se pode classificar a pesquisa como exploratória, pois visa proporcionar maior familiaridade com o problema, com vistas a torná-lo explícito ou a construir hipóteses.

Na sua abordagem quantitativa, a pesquisa traduz números, opiniões e informações, classificando e organizando-os por meio de métodos estatísticos. Sendo assim:

Muitos dos estudos de campo, bem como de levantamentos, podem ser classificados nessa categoria. Nos levantamentos, contudo, a preocupação do pesquisador é a de descrever com precisão essas características, utilizando instrumentos padronizados de coleta de dados, tais como questionários e formulários, que conduzem a resultados de natureza quantitativa. (Gil, 2010, p. 98).

Quanto aos procedimentos técnicos, a pesquisa se classifica como documental, pois foi realizada a análise de documentos fornecidos pela organização pública pesquisada, como relatórios de despesas e custos em geral com veículos do transporte escolar e folha de pagamento de funcionários; e como estudo de caso, dado que a pesquisa se desenvolveu em virtude de uma inquietação, qual seja, a busca da diminuição de gastos orçamentários pelo ente público, na esfera municipal de prestação de serviço de transporte escolar.

Far-se-á uma análise comparativa dos gastos relativos ao ano de 2015 na Prefeitura Municipal de São Miguel das Missões/RS, buscando, assim, a melhor forma de se executar o serviço de transporte escolar nesse município. 
Para alcançar as respostas da questão problema, foram coletadas informações no setor contábil, de recursos humanos e de licitações da Prefeitura Municipal de São Miguel das Missões, por meio de notas de empenho, contratos de licitações e folhas de pagamento, objetivando a apuração do custo empregado no transporte próprio e terceirizado, no período selecionado. Após a coleta das informações, foram elaboradas planilhas com todos os custos e despesas que interferem na formação do preço de custo do serviço de transporte escolar próprio. Posteriormente, foram elaborados os comparativos entre o custo atingido pelo serviço próprio e terceirizado. Os dados da pesquisa têm como referência o ano de 2015 e foram coletados no período entre setembro e novembro de 2016.

Quanto a seleção e tratamento dos dados, verificou-se que o serviço de transporte escolar no município é realizado por meio de veículos próprios e também de empresas terceirizadas, isto é, nas áreas em que o município não tem condições de disponibilizar um funcionário e veículo para executar o serviço, contrata uma empresa capacitada para realizar o trabalho, por meio de um processo licitatório.

Os veículos do transporte próprio foram adquiridos através de recursos próprios e também por meio de licitações do FNDE, às quais o município aderiu pelo programa federal Caminho da Escola. Atualmente, o ente público conta com 13 veículos para condução dos alunos, os quais possuem em média cinco anos de uso aproximadamente.

No transporte escolar terceirizado, tem-se a quantidade de sete veículos Kombi, com idade média de seis anos e meio, um micro-ônibus ano 2000 e três ônibus com idade média de 17,3 anos, totalizando 11 veículos, segundo informações da Secretaria de Educação do município (2016).

Em virtude da numerosa frota municipal, para este estudo foram considerados os gastos e as despesas com três tipos de transporte apenas, sendo eles: um micro-ônibus ano 2009, um ônibus ano 2012 e uma Kombi ano 2013. Quanto aos serviços terceirizados, foram analisados os mesmos tipos de veículos, porém com ano de fabricação distinto, pois os veículos com até 12 lugares colocados à disposição dos serviços contratados podem possuir até dez anos de uso, e 17 anos de uso é a exigência máxima para os ônibus com até 45 lugares.

Procurou-se equiparar as condições dos veículos para um melhor resultado, na medida do possível. As despesas de um ônibus ano 2000, uma Kombi ano 2002 e um micro-ônibus ano 2000 de empresas terceirizadas foram avaliados neste trabalho.

\section{APRESENTAÇÃO E DISCUSSÃO DOS RESULTADOS}


O transporte escolar é fundamental no contexto de inserção do aluno no sistema educacional. Avaliar essa ferramenta, por sua vez, é essencial no que tange aos compromissos do poder público para com o dinheiro público.

Dessa forma, a partir do levantamento de dados efetuado no município, podese constatar que as despesas com licenciamento e com o Seguro DPVAT (Danos Pessoais Causados por Veículos Automotores de Vias Terrestres) do ente público são pagas sempre em cota única, no mês de janeiro de cada ano. Ônibus e micro-ônibus têm despesas com DPVAT de $R$ \$ 246,48 , e o veículo Kombi tem o custo de $R \$$ 105,25 com esse licenciamento. Também há as despesas com vistoria mecânica, inspeção veicular e regularização de tacógrafo, vistoria realizada a cada dois anos em veículo escolar, ou seja, consumida pela metade em cada exercício.

No montante de gastos com pessoal na Secretaria de Educação do município, o cargo de motorista soma a quantidade de 13 servidores atualmente. Pode-se verificar que há diferentes valores de salários entre esses funcionários, em razão das variáveis tempo de serviço e horas extras realizadas.

Essas despesas com salários para o ente público incluem os encargos com o Fundo de Aposentadoria e Benefícios do Servidor (FABS) e o Instituto de Previdência do Estado do Rio Grande do Sul (IPERGS). Foram escolhidos três entre os 13 servidores, calculando-se, por meio de uma mediana, o valor anual de custo com salário e encargos de $\mathrm{R} \$ 28.703,67$. Na figura 1 , pode-se verificar os valores de custo por funcionário em relação a um mês.

Média de custo mensal de salários e encargos por motorista

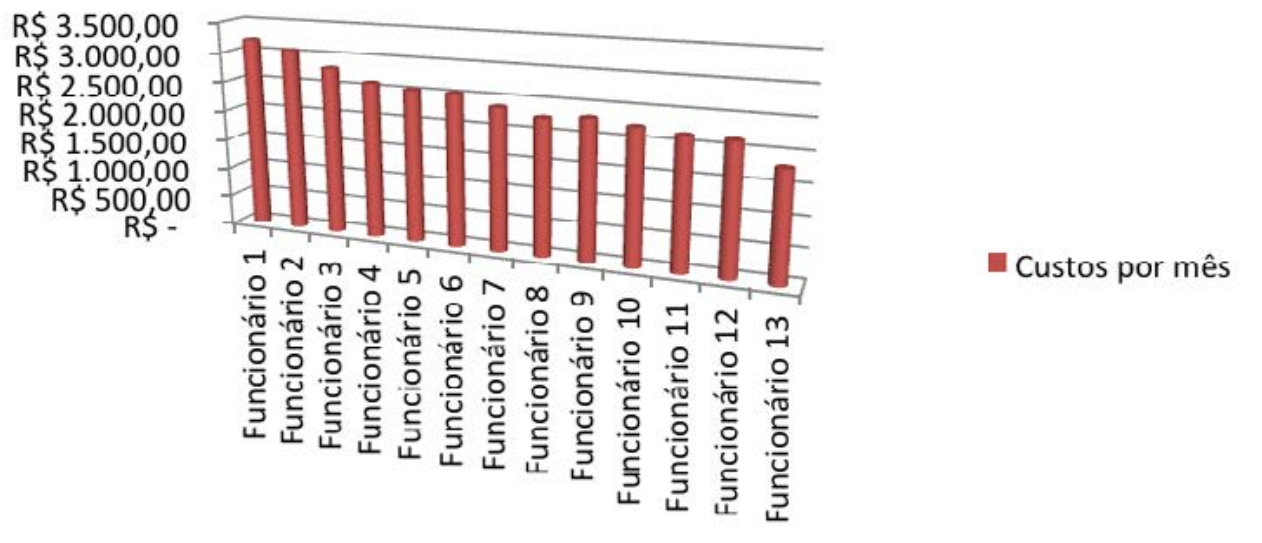

Figura 1 - Média de custo mensal em salários e encargos por motorista Fonte: dados da pesquisa (2016). 
A figura 1 traz todos os valores gastos por mês com pessoal, o que representa uma disparidade entre o Funcionário 13 e o Funcionário 01 de $56,61 \%$, somando um total de $\mathrm{R} \$ 16.692,88$ a mais de despesa anual com este último. Essa diferença se dá em razão do número de horas extras realizadas e do tempo de serviço, como já mencionado.

O valor geral de gastos com pessoal do cargo de motorista chegou a $R \$$ $328.458,29$, incluindo-se também $R \$ 31.068,85$ de FABS e $R \$ 25.826,71$ de IPERGS no ano de 2015, perfazendo o valor de $\mathrm{R} \$ 385.353,85$ ao ano. São ainda somados no custo total a gratificação adicional por tempo de serviço, a gratificação por exercício de função de natureza especial, as horas extras, as obrigações de férias, o décimo terceiro e o vale-alimentação.

Nos gastos por veículo, estão incluídos vários tipos de produtos, como mão de obra, combustível, licenciamentos, entre outros, conforme se pode analisar na tabela 1, referente ao veículo 01 (modelo ônibus), que percorre 138 quilômetros por dia, ao custo por quilômetro rodado de $\mathrm{R} \$ 2,56$.

Tabela 1 - Gastos do veículo ônibus no ano de 2015

\begin{tabular}{|c|c|c|c|c|}
\hline Veículo 1 & $\begin{array}{l}\text { Órgão público } \\
\text { municipal }\end{array}$ & Fab./ & \multicolumn{2}{|c|}{ Rend./Combustível: $3,98 \mathrm{~km} /$ litro } \\
\hline $\begin{array}{l}\text { Descrição do } \\
\text { carro }\end{array}$ & $\begin{array}{l}\text { ÔNIBUS VW } \\
\text { INDUSCAR }\end{array}$ & & IPVA & Isento \\
\hline \multirow{6}{*}{\multicolumn{2}{|c|}{ ÔNIBUS }} & Licen & amento DPVAT & $\mathrm{R} \$ 246,48$ \\
\hline & & Licença & nspeção Veicular & $\mathrm{R} \$ 380,00$ \\
\hline & & Lic & ça Tacógrafo & $\mathrm{R} \$ 765,00$ \\
\hline & & & toria Detran & Isento \\
\hline & & Segur & Passageiros $/ 3^{\circ} \mathrm{s}$ & $\mathrm{R} \$ 886,33$ \\
\hline & & Estima & va Manut. Peças & $\mathrm{R} \$ 8.795,16$ \\
\hline \multirow{2}{*}{$\begin{array}{l}\text { Média de salário } \\
\text { motorista por } \\
\text { mês }\end{array}$} & \multirow[b]{2}{*}{$\mathrm{R} \$ 2.391,97$} & Encar & os Salário anual & $\mathrm{R} \$ 28.703,67$ \\
\hline & & Encargo & $\begin{array}{l}\text { FABS/IPE anual já } \\
\text { incluso }\end{array}$ & $\mathrm{R} \$ 4.376,59$ \\
\hline \multirow{6}{*}{$\begin{array}{l}\text { Cotação de } \\
\text { venda } \\
\text { Cotação } \\
\text { pela } \\
\text { internet }\end{array}$} & \multirow{6}{*}{$\begin{array}{c}\mathrm{R} \$ 50.000,00 \\
\text { Consumo de } \\
6.953 \text { litros de } \\
\text { combustível/ano }\end{array}$} & Estimat & a de Combustível & $\mathrm{R} \$ 20.570,85$ \\
\hline & & \multicolumn{2}{|c|}{ Óleos Lubrificantes e Filtros } & $\mathrm{R} \$ 931,99$ \\
\hline & & \multicolumn{2}{|c|}{ Pneus novos } & $\mathrm{R} \$ 9.480,00$ \\
\hline & & \multicolumn{2}{|c|}{ Total Custos anuais } & $\mathrm{R} \$ \mathbf{7 0 . 7 5 9 , 4 8}$ \\
\hline & & \multicolumn{2}{|c|}{ Estimativa $\mathbf{k m}$ anuais } & $27.600,00$ \\
\hline & & \multicolumn{2}{|c|}{ Custo km rodado } & $R \$ 2,56$ \\
\hline
\end{tabular}

Fonte: dados da pesquisa, 2016. 
Na tabela 2, com dados do veículo 02 (modelo Kombi), o qual percorre 145,3 quilômetros por dia, pode-se observar que o custo chegou a $R \$ 1,65$.

Tabela 2 - Gastos do veículo ônibus no ano de 2015

\begin{tabular}{|c|c|c|c|c|c|}
\hline Veícul & & $\begin{array}{c}\text { Órgão público } \\
\text { municipal }\end{array}$ & $\begin{array}{l}\text { Fab.l } \\
\text { Mod.: } \\
2013\end{array}$ & $\begin{array}{r}\text { Rend./CoI } \\
9,0 \mathrm{kr}\end{array}$ & $\begin{array}{l}\text { lbustível: } \\
\text { //litro }\end{array}$ \\
\hline Descrição c & carro & $\begin{array}{c}\text { KOMBI } \\
\text { STANDART } \\
1.4 \\
\end{array}$ & & & Isento \\
\hline & & & & & $\mathrm{R} \$ 105,25$ \\
\hline & & & Licença I & ção Veicular & $\mathrm{R} \$ 380,00$ \\
\hline & KOMRI & & Licen & acógrafo & $\mathrm{R} \$ 57,50$ \\
\hline & RUIVIDI & & Vist & Detran & Isento \\
\hline & & & Seguro & ageiros $/ 3^{\circ} \mathrm{s}$ & $\mathrm{R} \$ 886,33$ \\
\hline & & & Estimati & anut. Peças & $\mathrm{R} \$ 4.292,27$ \\
\hline Média de & & & Encargc & lário anual & $\mathrm{R} \$ 28.703,67$ \\
\hline $\begin{array}{c}\text { salarıo } \\
\text { motorista por } \\
\text { mês }\end{array}$ & & $2.391,97$ & $\begin{array}{l}\text { Encar } \\
\text { anu }\end{array}$ & $\begin{array}{l}\text { ABS/IPE } \\
\text { incluso }\end{array}$ & $\mathrm{R} \$ 4.376,59$ \\
\hline Cotação FIPE & & $30.609,00$ & & $\begin{array}{l}\text { Iva de } \\
\text { stível }\end{array}$ & $\mathrm{R} \$ 11.533,01$ \\
\hline Cotação pela & Consu & o de $3.228,97$ & Óleos Luk & intes e Filtros & $\mathrm{R} \$ 1.054,97$ \\
\hline $\begin{array}{l}\text { Fundaccão } \\
\text { Instituto de }\end{array}$ & litros de & ombustível/ano & & novos & $\mathrm{R} \$ 1.016,00$ \\
\hline & & & Total C & os anuais & $\mathrm{R} \$ 48.029,00$ \\
\hline & & & Estimat & ims anuais & $29.060,73$ \\
\hline & & & Custo & $\mathrm{m}$ rodado & $\mathrm{R} \$ 1,65$ \\
\hline
\end{tabular}

Fonte: dados da pesquisa, 2016.

Em relação ao veículo 03 (micro-ônibus), que percorre 127,5 quilômetros por dia, o custo chegou a $\mathrm{R} \$ 1,78$, conforme se pode notar na tabela 3 . 
Tabela 3 - Gastos do veículo ônibus no ano de 2015

\begin{tabular}{|c|c|c|c|c|}
\hline \multicolumn{2}{|r|}{$\begin{array}{l}\text { Orgão } \\
\text { público }\end{array}$} & $\begin{array}{c}\text { Fab/Mod: } \\
2009\end{array}$ & \multicolumn{2}{|c|}{$\begin{array}{c}\text { Rend/ Combustível: } \\
13,69 \mathrm{~km} / \text { litro }\end{array}$} \\
\hline Descrição do carro & ÔNIBUS 2009 & & IPVA & Isento \\
\hline \multirow{6}{*}{\multicolumn{2}{|c|}{ MICRO-ÔNIBUS }} & \multicolumn{2}{|c|}{ Licenciamento DPVAT } & $\mathrm{R} \$ 246,48$ \\
\hline & & \multicolumn{2}{|c|}{ Licença Inspeção Veicular } & $\mathrm{R} \$ 380,00$ \\
\hline & & \multicolumn{2}{|c|}{ Licença Tacógrafo } & $\mathrm{R} \$ 380,00$ \\
\hline & & \multicolumn{2}{|c|}{ Vistoria Detran } & Isento \\
\hline & & \multicolumn{2}{|c|}{ Seguro Passageiros $/ 3^{\circ} \mathrm{s}$} & $\mathrm{R} \$ 1.762,46$ \\
\hline & & \multicolumn{2}{|c|}{ Estimativa Manut. Peças } & $\mathrm{R} \$ 5.299,70$ \\
\hline \multirow[b]{2}{*}{$\begin{array}{l}\text { Média Salário } \\
\text { Motorista: }\end{array}$} & \multirow[b]{2}{*}{$\mathrm{R} \$ 2.391,97$} & \multicolumn{2}{|c|}{ Encargos Salário anual } & $\mathrm{R} \$ 28.703,67$ \\
\hline & & \multicolumn{2}{|c|}{$\begin{array}{c}\text { Encargos FABS/IPE anual } \\
\text { já incluso }\end{array}$} & $\mathrm{R} \$ 4.376,59$ \\
\hline \multirow{6}{*}{$\begin{array}{l}\quad \text { Cotação FIPE } \\
\text { Cotação pela Fun- } \\
\text { dação Instituto de } \\
\text { Pesquisas Econô- } \\
\text { micas }\end{array}$} & $\mathrm{R} \$ 47.405,00$ & \multicolumn{2}{|c|}{ Estimativa de Combustível } & $\mathrm{R} \$ 5.522,99$ \\
\hline & \multirow{5}{*}{$\begin{array}{c}\text { Consumo de } \\
1.862,00 \text { litros de } \\
\text { combustível/ano }\end{array}$} & \multicolumn{2}{|c|}{$\begin{array}{c}\text { Óleos Lubrificantes e } \\
\text { Filtros }\end{array}$} & $\mathrm{R} \$ 556,00$ \\
\hline & & \multicolumn{2}{|c|}{ Pneus novos } & $\mathrm{R} \$ 2.560,00$ \\
\hline & & \multicolumn{2}{|c|}{ Total Custos anuais } & $\mathrm{R} \$ 45.411,30$ \\
\hline & & \multicolumn{2}{|c|}{ Estimativa kms anuais } & $25.500,00$ \\
\hline & & \multicolumn{2}{|c|}{ Custo por km rodado } & $\mathrm{R} \$ 1,78$ \\
\hline
\end{tabular}

Fonte: dados da pesquisa, 2016.

Em se tratando de cálculo de depreciação, o ente público em questão não o considera em seus indicadores, devido aos veículos estarem dentro do prazo de regulamentação, conforme a STN. No entanto, é importante destacar informações levantadas da STN (2014, p. 148):

A apuração da depreciação, amortização e exaustão deve ser feita mensalmente, quando o item do ativo estiver em condições de uso. Ao final de cada exercício financeiro a entidade deve realizar a revisão da vida útil e do valor residual do item do ativo. Ao fim da depreciação o valor líquido contábil deve ser igual ao valor residual.

Tomando por base os valores do quilômetro rodado do transporte escolar do órgão público em análise, deve-se também observar os valores pagos pelo serviço de transporte terceirizado (Tabela 4). 
Tabela 4 - Informações do transporte terceirizado

\begin{tabular}{c|c|c|c|c}
\hline Roteiro/veículo & $\begin{array}{c}\text { Quilômetros } \\
\text { percorridos }\end{array}$ & $\begin{array}{c}\text { Custo por } \\
\text { quilômetro }\end{array}$ & Total diário & Total anual \\
\hline Roteiro 07 (Kombi) & $50 \mathrm{~km} / \mathrm{dia}$ & $\mathrm{R} \$ 4,08$ & $\mathrm{R} \$ 204,00$ & $\mathrm{R} \$ 40.800,00$ \\
\hline $\begin{array}{c}\text { Roteiro 05 (Micro- } \\
\text { Ônibus) }\end{array}$ & $65 \mathrm{~km} / \mathrm{dia}$ & $\mathrm{R} \$ 3,33$ & $\mathrm{R} \$ 216,45$ & $\mathrm{R} \$ 43.290,00$ \\
\hline Roteiro 11 (Ônibus) & $101 \mathrm{~km} / \mathrm{dia}$ & $\mathrm{R} \$ 4,30$ & $\mathrm{R} \$ 434,30$ & $\mathrm{R} \$ 86.860,00$ \\
\hline
\end{tabular}
Fonte: dados da pesquisa, 2016.

Considera-se que os roteiros terceirizados variam em valor por quilômetro, conforme a distância percorrida, devido aos custos fixos que a empresa tem e que independem das condições estabelecidas no contrato decorrente do processo licitatório. Os valores contratados sofrem reajuste de acordo com a variação do preço dos combustíveis. O valor gasto pelo ente público com empresas que prestaram serviço de transporte escolar no ano de 2015 somou um total de $\mathrm{R} \$ 522.560,66$.

Tabela 5 - Comparativo de custo por quilômetro

\begin{tabular}{c|c|c|c}
\hline Veículo & Próprio & Terceirizado & $\begin{array}{c}\text { Percentual de custo com } \\
\text { terceirização em relação ao } \\
\text { transporte próprio }\end{array}$ \\
\hline Kombi & $\mathrm{R} \$ 1,65 / \mathrm{km}$ & $\mathrm{R} \$ 4,08 / \mathrm{km}$ & $247 \%$ \\
\hline Micro-ônibus & $\mathrm{R} \$ 1,87 / \mathrm{km}$ & $\mathrm{R} \$ 3,33 / \mathrm{km}$ & $178,07 \%$ \\
\hline Ônibus & $\mathrm{R} \$ 2,56 / \mathrm{km}$ & $\mathrm{R} \$ 4,30 / \mathrm{km}$ & $167,97 \%$ \\
\hline
\end{tabular}

Fonte: dados da pesquisa, 2016

O comparativo demonstra o custo elevado com o tipo de transporte terceirizado, o que equivale aproximadamente a $36,55 \%$ da despesa total em transporte escolar. O total gasto em transporte escolar chegou ao montante de $\mathrm{R} \$$ 1.429.690,69. O custo dos roteiros terceirizados 05,07 e 11 analisados pelo presente trabalho soma um total diário de $\mathrm{R} \$ 854,75$, o qual foi comparado ao custo do transporte próprio, que, sendo relacionado à mesma quilometragem, poderia ser executado ao valor de $\mathrm{R} \$ 462,91$ por dia.

No período de um exercício financeiro, o ente público tem um gasto com o transporte terceirizado de $R \$ 170.950,00$ nos roteiros analisados; já se o serviço fosse realizado pelo ente público, com veículos próprios, o gasto anual seria de $R \$$ 92.582,00 para os mesmos roteiros.

\section{CONSIDERAÇÕES FINAIS}

O presente estudo pretendeu demonstrar de forma abrangente a importância da contabilidade nas organizações, especificamente na área pública, e procurou 
evidenciar normas e legislações que regem organizações públicas, especificamente no âmbito municipal. O objetivo deste trabalho foi levantar dados com relação a custos e despesas relacionadas ao transporte próprio e terceirizado na organização, em específico na Secretaria de Educação, por meio de comparativa e presumível conclusão do melhor meio a ser utilizado, o transporte próprio ou o terceirizado.

A questão problema surgiu de uma inquietação a respeito do montante de gastos e despesas enfrentados no ente público, os quais, por vezes, ultrapassam o valor orçado para o período de um exercício financeiro. É analisada a qualidade dos veículos terceirizados utilizados para executar o serviço, já que é estabelecido um padrão de qualidade nas cláusulas do contrato entre a prefeitura e a empresa prestadora de serviço. Assim, buscou-se analisar qual a forma mais viável de executar o serviço de transporte escolar, se o serviço próprio ou o serviço terceirizado.

$O$ aprofundamento da pesquisa revela as vantagens ou desvantagens na aquisição de mais veículos e contratação de servidores, a fim de reduzir os gastos com o pagamento de empresas terceirizadas para a prestação de serviço de transporte escolar.

A efetividade do serviço público é fundamental para o cidadão, e diagnosticar se o serviço próprio é viável diante do serviço terceirizado oportuniza uma série de implicações nas decisões do gestor, decisões estas de cunho administrativo, legal e de segurança. Além de optar pelo serviço viável economicamente, o gestor também precisa optar pelo serviço que traga maior segurança ao usuário.

Considera-se, portanto, este estudo de grande importância, pois permite ao ente público tomar suas decisões quanto à melhor forma de executar o serviço de transporte escolar no âmbito municipal, diminuindo, assim, dispêndios orçamentários em função dessa necessidade. Ainda, é possível tomar decisões mais bem embasadas, analisando-se, em estudos futuros, gastos com transporte escolar durante três anos por essa organização. 


\section{REFERÊNCIAS}

Andrade, N. A. (2013). Contabilidade pública na gestão municipal (5. ed.). São Paulo: Atlas.

Brasil. (2000). Lei complementar $n^{\circ} 101$, de 4 de maio de 2000. Estabelece normas de finanças públicas voltadas para a responsabilidade na gestão fiscal e dá outras providências. Recuperado de http://www.planalto.gov.br/ccivil_03/leis/ LCP/Lcp101.htm

Brasil. (1964). Lei $n^{\circ} 4.320$, de 17 de março de 1964. Institui normas gerais de Direito Financeiro para elaboração e controle dos orçamentos e balanços da União, dos Estados, os Municípios e do Distrito Federal. Recuperado de https:// www.planalto.gov.br/ccivil_03/leis/L4320.htm

Brasil. (1993). Lei $n^{\circ}$ 8.666, de 21 de junho de 1993. Institui normas para licitações e contratos da Administração Pública. Recuperado de https://www.planalto.gov.br/ccivil_03/leis/L8666cons.htm

Brasil. (1996). Lei $n^{\circ}$ 9.394, de 20 de dezembro de 1996. Estabelece as diretrizes e bases da educação nacional. Recuperado de http://www.planalto.gov.br/ ccivil_03/leis/L9394.htm

Brasil. (2003). Lei $n^{\circ}$ 10.709, de 31 de julho de 2003. Acrescenta incisos aos artigos 10 e 11 da Lei $n^{\circ}$ 9.394, de 20 de dezembro de 1996, que estabelece as diretrizes e bases da educação nacional. Recuperado de http://www.planalto.gov. br/ccivil_03/leis/2003/L10.709.htm

Brasil. (2004). Lei $n^{\circ}$ 10.880, de 09 de junho de 2004. Institui o Programa Nacional de Apoio ao Transporte do Escolar - Pnate e o Programa de Apoio aos Sistemas de Ensino para Atendimento à Educação de Jovens e Adultos. Recuperado de http://www.planalto.gov.br/ccivil_03/_ato2004-2006/2004/lei//10.880.htm

Brasil. (2007). Lei $n^{\circ} 11.494$, de 20 de junho de 2007. Regulamenta o Fundo de Manutenção e Desenvolvimento da Educação Básica e de Valorização dos Profissionais da Educação. Recuperado de http://www.planalto.gov.br/ccivil_03/_ ato2007-2010/2007/lei/111494.htm

Fundo Nacional de Desenvolvimento da Educação (FNDE). (2016). Transporte escolar: Apresentação. Recuperado de http://www.fnde.gov.br/programas/ transporte-escolar/transporte-escolar-apresentacao

Gil, A. C. (2010). Como elaborar projetos de pesquisa (5. ed.). São Paulo: Atlas. Kohama, H. (2013). Contabilidade pública: Teoria e prática. São Paulo: Atlas.

Ministério da Fazenda. (2014). Manual de contabilidade aplicada ao setor público (6. ed.). Brasília: Ministério da Fazenda/Secretaria do Tesouro Nacional. 
Piscitelli, R. B., \& Timbó, M. Z. F. (2012). Contabilidade pública: Uma abordagem da administração financeira pública. São Paulo: Atlas.

Rio Grande do Sul. (2008). Lei n 12.882, de 03 de janeiro de 2008. Institui o Programa Estadual de Apoio ao Transporte Escolar no Rio Grande do Sul. Recuperado de http://www.educacao.rs.gov.br/pse/html/arquivos/rel_mun_lei_peate.pdf

Silva, V. L. (2014). A nova contabilidade aplicada ao setor público: Uma abordagem prática. São Paulo: Atlas. 